\title{
Genetic and environmental variation in bovine milk infrared spectra
}

\author{
Qiuyu Wang, ${ }^{1}$ Alex Hulzebosch, and Henk Bovenhuis \\ Animal Breeding and Genomics Centre, Wageningen University, PO Box 338, 6700AH, Wageningen, the Netherlands
}

\begin{abstract}
Fourier transform infrared (FTIR) spectroscopy is widely used to determine milk composition. In this study, 1,060 milk infrared wavenumbers ranging from 925 to $5,008 \mathrm{~cm}^{-1}$ of 1,748 Holstein Friesian cows on 371 herds in the Netherlands were available. The extent to which infrared wavenumbers are affected by genetic and environmental factors was investigated. Inter-herd heritabilities of 1,060 infrared wavenumbers ranged from 0 to 0.63 , indicating that the genetic background of infrared wavenumbers differs considerably. The majority of the wavenumbers have moderate to high inter-herd heritabilities ranging from 0.20 to 0.60 . The diacylglycerol O-acyltransferase 1 (DGAT1), stearoyl-CoA desaturase (SCD1), к-casein (CSN3), and $\beta$-lactoglobulin $(L G B)$ polymorphisms are known to have a large effect on milk composition, and therefore we studied the effects of these polymorphisms on infrared wavenumbers. The DGAT1 polymorphism had highly significant effects on many wavenumbers. In contrast, the $S C D 1$ polymorphism did not significantly affect any of the wavenumbers. The $S C D 1$ is known to have a strong effect on the content of C10:1, C12:1, C14:1, and C16:1 fatty acids. Therefore, these results suggest that FTIR spectra contain little direct information on these monounsaturated fatty acids. The CSN3 and $L G B$ polymorphisms had significant effects on a few wavenumbers. Differences between herds explained 10 to $25 \%$ of the total variance for most wavenumbers. This suggests that the wavenumbers of milk FTIR spectra are indicative for differences in feeding and management between herds. The wavenumbers between 1,619 and $1,674 \mathrm{~cm}^{-1}$ and between 3,073 and $3,667 \mathrm{~cm}^{-1}$ are strongly influenced by water absorption and usually excluded when setting up prediction equations. However, we found that some of the wavenumbers in the water absorption region are affected by the DGAT1 polymorphism and lactation stage. This suggests that these wavenumbers contain useful information regarding milk composition.
\end{abstract}

Key words: bovine milk, FTIR wavenumbers, heritability, herd, genetic polymorphisms

Received October 5, 2015.

Accepted April 3, 2016.

${ }^{1}$ Corresponding author: qiuyu.wang@wur.nl

\section{INTRODUCTION}

Milk produced by dairy cows is a complex product consisting of many components (Jelen, 2007). However, at present, only fat and protein content are routinely recorded and considered in most dairy cattle breeding programs (Miglior et al., 2005). Despite this, both from a nutritional and a manufacturing perspective, detailed fat and protein composition are of interest. Several studies suggested protein composition is related to milk coagulation and cheese yield (e.g., Wedholm et al., 2006), since a greater casein content is preferable for cheese making. Due to its relatively high concentration of SFA, the consumption of bovine milk fat has been associated with negative effects on human health (e.g., German and Dillard, 2006), and therefore changing milk fat composition by means of selective breeding might be of interest. Moreover, milk composition can serve as an indicator for the cow's health status (e.g., Vlaeminck et al., 2006; Van Haelst et al., 2008) and methane emission (e.g., Chilliard et al., 2009). For breeding and management purposes, large-scale routinely collected measurements are needed and therefore traits should be easy to measure at relatively low costs. Analytical methods such as gas chromatography to quantify milk fat composition, or HPLC and capillary zone electrophoresis to quantify milk protein composition, are expensive and time-consuming. Therefore, these methods are less suited for large-scale routine measurements.

Fourier transform infrared (FTIR) spectroscopy is a fast and cost-effective method widely used to determine milk composition. It is the standard method for routine quantification of fat, protein, and lactose content of milk (ICAR, 2012). Several studies showed that FTIR also can be used to determine milk fat composition (e.g., Soyeurt et al., 2006; Rutten et al., 2009). Other studies investigated possibilities to predict milk protein composition based on FTIR (Bonfatti et al., 2011; Rutten et al., 2011a). Furthermore, recent research reported the ability of infrared spectroscopy to predict traits such as milk coagulation, ketone bodies, and energy status of dairy cows (De Marchi et al., 2014).

Some studies analyzed the genetic background of infrared wavenumbers (Soyeurt et al., 2010; Bittante and Cecchinato, 2013). Soyeurt et al. (2010) analyzed 
infrared spectra of 1,594 first parity Holstein cows and found substantial differences in heritability between wavenumbers and concluded that not all infrared wavenumbers are of genetic interest. Bittante and Cecchinato (2013) studied the infrared spectra of 1,064 Brown Swiss cows and reported that approximately $30 \%$ of the wavenumbers have heritability larger than 0.10 .

Besides quantifying the combined action of all genes on infrared wavenumbers, it might be of interest to study the effects of individual genes with known and large effect on milk composition. Polymorphisms in diacylglycerol O-acyltransferase 1 (DGAT1), stearoylCoA desaturase 1 (SCD1), $\kappa$-casein (CSN3), and $\beta$-lactoglobulin $(L G B)$ have been shown to have important effects on milk composition (e.g., Schennink et al., 2008; Heck et al., 2009). Their effects on individual infrared wavenumbers can provide insight in the information that is captured by the FTIR spectra. Furthermore, it has been shown that FTIR can be used to predict $L G B$ genotypes (Rutten et al., 2011b) and CSN1S1 haplotypes (Berget et al., 2010). Quantifying the effects of DGAT1, SCD1, and CSN3 polymorphisms on individual infrared wavenumbers can give insight in the possibilities of predicting genotypes for these polymorphisms based on FTIR.

It is well known that milk composition is also affected by feed and management strategies, for example, feed composition influences milk fat content and fat composition (e.g., Chilliard et al., 2007) and dietary energy intake influences milk protein content (Emery, 1978). Consumers have increasing interest in the authenticity of milk as they purchase biological and organic products at a higher price. Infrared spectroscopy might be one of the methods that enable discriminating milk samples produced by cows fed different diets (Valenti et al., 2013). Quantifying herd effects will give insight in the extent to which feed and management differences are reflected by individual wavenumbers. Herd effects for individual infrared wavenumbers of bovine milk have not been quantified before.

The aim of this study was to quantify the contribution of genetic and environmental effects to the variation in milk infrared wavenumbers. Furthermore, we aimed at quantifying the effects of polymorphisms in DGAT1, $S C D 1, C S N 3$, and $L G B$ on milk infrared wavenumbers.

\section{MATERIALS AND METHODS}

\section{Data}

In this study, one morning milk sample from 1,748 first-parity Holstein Friesians cows located in 371 herds was collected for analysis. The data were collected from
February to March 2005. All cows had at least $87.5 \%$ Holstein Friesian genes. The population consisted of 5 large paternal half-sib families from proven sires (98196 daughters per sire), and 50 small paternal half-sib families from test sires (8-23 daughters per sire), as well as 168 cows descending from 44 other proven sires (1-25 daughters per sire) to ensure at least 3 cows per herd. The pedigree of the cows was provided by CRV (cooperative cattle improvement organization, Arnhem, the Netherlands).

Milk samples were conserved using sodium azide $(0.03 \% \mathrm{wt} / \mathrm{wt})$ at $4^{\circ} \mathrm{C}$. Subsequently, FTIR spectra were recorded in a $10-\mathrm{mL}$ milk sample using the MilkoScan FT 6000 equipment (Foss, Hillerød, Denmark) at the certified laboratory of the Milk Control Station (Zutphen, the Netherlands). All milk samples used in this study were analyzed on the same MilkoScan FT 6000. The FTIR spectra consisted of the transmittance values measured at 1,060 wavenumbers ranging from 925 to $5,008 \mathrm{~cm}^{-1}$.

\section{Genotypes}

Blood samples were collected for DNA isolation. The genotyping procedure for DGAT1 K232A and SCD1 A239V polymorphisms were described by Schennink et al. (2008). Genotypes of CSN3 were determined as described by Heck et al. (2009). The polymorphisms associated with the known protein variants for $L G B$ were genotyped using a SNaPshot assay as described by Visker et al. (2011).

Among the 1,748 cows with FTIR data, 1,625 cows had DGAT1 genotypes, 1,579 cows had SCD1 genotypes, 1,534 cows had CSN3 genotypes, and 1,542 cows had $L G B$ genotypes. For some cows the genotypes were missing because either no DNA sample was available or the sample could not be genotyped unambiguously. The allele frequencies were $60.0 \%$ for A allele and $40.0 \%$ for K allele of DGAT1, $73.0 \%$ for A allele and $27.0 \%$ for $\mathrm{V}$ allele of $S C D 1,58.3 \%$ for A allele and $41.7 \%$ for B allele of $L G B$, and $60.4,30.1$, and $9.5 \%$ for $C S N 3 \mathrm{~A}, \mathrm{~B}$, and E allele, respectively.

\section{Statistical Analysis}

A series of analyses were performed to quantify the effects of several factors on the 1,060 infrared wavenumbers. The following model was used:

$$
\begin{aligned}
y_{i j k l m} & =\mu+\beta_{1} \times \text { lactst }_{i j k l m}+\beta_{2} \times \text { afc }_{i j k l m}+\text { season }_{i} \\
& + \text { sirecode }_{j}+\text { date }_{k}+\text { herd }_{l}+a_{m}+e_{i j k l m}
\end{aligned}
$$


where $y_{i j k l m}$ is the transmittance value of the infrared wavenumber; $\mu$ is the general mean; lactst $_{i j k l m}$ is a covariate for the effect of lactation stage (in days) with regression coefficient $\beta_{1} ; a f c_{i j k l m}$ is a covariate for the effect of age at first calving with regression coefficient $\beta_{2}$; season $_{i}$ is the fixed effect season of calving (JuneAugust 2004, September-November 2004, or December 2004-January 2005); sirecode $e_{j}$ is the fixed effect accounting for possible differences in genetic level between the groups of proven bull daughters and young bull daughters; date $e_{k}$ is the fixed effect accounting for the effect of $17 \mathrm{~d}$ at which FTIR analyses of milk samples took place; $h e r d_{l}$ is a random effect of herd $k$, distributed as $N\left(0, \mathbf{I} \sigma_{h}^{2}\right)$, with identity matrix $\mathbf{I}$ and herd variance $\sigma_{h}^{2} ; a_{m}$ is a random additive genetic effect of animal $l$, distributed as $N\left(0, \mathbf{A} \sigma_{a}^{2}\right)$, with additive genetic relationship matrix $\mathbf{A}$ and the additive genetic variance $\sigma_{a}^{2}$. The additive genetic relationship matrix was constructed based on 12,548 animals. Finally, $e_{i j k l m}$ is a random residual effect, distributed as $N\left(0, \mathbf{I} \sigma_{e}^{2}\right)$, with identity matrix $\mathbf{I}$ and error variance $\sigma_{e}^{2}$.

The inter-herd heritability for individual wavenumbers was calculated as

$$
h^{2}=\frac{\sigma_{a}^{2}}{\sigma_{a}^{2}+\sigma_{h}^{2}+\sigma_{e}^{2}} .
$$

ASReml (Gilmour et al., 2009) was used to perform single trait analyses to assess the significance ( $P$-values) of the fixed effects and REML estimates of variance components.

The effects of the DGAT1, SCD1, CSN3, and $L G B$ polymorphisms were estimated using model [1] but extended with a fixed effect. The effects of the 4 polymorphisms were determined in separate analyses. Individuals whose genotype was missing were included in the analysis by assigning them to a separate genotype class. Missing genotypes appeared to be randomly distributed across other effects in the model.

Significance tests for systematic environmental factors were performed for each of the 1,060 wavenumbers. To adjust for multiple testing we used a Bonferroni correction. To determine the number of independent traits a principal component analysis was performed on the FTIR spectra, indicating that $99 \%$ of the variation can be described based on 45 principal components (result not shown). To adjust for multiple testing, we therefore assumed 50 independent tests and consequently an effect was considered significant if $-\log _{10}(P)$ was larger than 3 [i.e., $\left.-\log _{10}(0.05 / 50)\right]$, where $P$ represents the significance of the effect.

\section{RESULTS}

The mean, 1st percentile, and 99th percentile of the 1,060 milk infrared wavenumbers are shown in Figure 1. Infrared wavenumbers between 1,619 and $1,674 \mathrm{~cm}^{-1}$ and between 3,073 and $3,667 \mathrm{~cm}^{-1}$ showed larger variation than others. These wavenumbers represent the absorption peaks of water and will be referred to as the water absorption region.

\section{Fixed Effects}

Age at first calving, season of calving, and differences between groups of proven and young bull daughters did not show significant effects on any of the 1,060 wavenumbers. Lactation stage had significant effects on 457 wavenumbers. The highest $-\log _{10}(P)$ of 15.6 for lactation stage was found for wavenumber $2,495 \mathrm{~cm}^{-1}$. Date of FTIR analysis had significant effect on $80 \%$ of the wavenumbers, especially on the wavenumbers in the water absorption region. The $-\log _{10}(P)$ of lactation stage and date of FTIR analysis are shown in Figure 2.

\section{Variance Components}

Genetic, herd, and residual variances as a fraction of the total phenotypic variance are shown in Figure 3. Genetic factors explained more than $40 \%$ of the total variation for wavenumbers from 925 to $1,257 \mathrm{~cm}^{-1}$, 1,454 to $1,465 \mathrm{~cm}^{-1}, 2,811$ to $2,973 \mathrm{~cm}^{-1}$, and 4,122 to $5,008 \mathrm{~cm}^{-1}$. Furthermore, for most of the wavenumbers from 1,693 to $2,479 \mathrm{~cm}^{-1}$ more than $40 \%$ of the total variation was due to genetic factors except for 1,724 $\mathrm{cm}^{-1}(19.6 \%)$ and $1,770 \mathrm{~cm}^{-1}(29.3 \%)$. On the other hand, genetic factors explained almost no variation and residual variance accounted for more than $90 \%$ of the total phenotypic variance for most of the wavenumbers in the water absorption region. An exception was some wavenumbers near $3,154 \mathrm{~cm}^{-1}$ for which genetic factors explained up to $18.7 \%$ of the total variation.

Inter-herd heritabilities of the 1,060 wavenumbers were 0.36 on average, ranging from 0 to 0.63 . In total, 197 wavenumbers had heritabilities lower than 0.20 and 291 wavenumbers had heritabilities between 0.20 and 0.40 . Five hundred sixty wavenumbers had heritabilities between 0.40 and 0.60 , and 12 wavenumbers had heritabilities larger than 0.60 .

For 806 wavenumbers, differences between herds contributed more than $10 \%$ of the total phenotypic variance. The herd variance accounted for up to $28 \%$ of the total phenotypic variance for wavenumber $3,717 \mathrm{~cm}^{-1}$, which was the wavenumber with the largest contribution of herd variance. 


\section{Effects of DGAT1, SCD1, CSN3, and LGB}

Figure 4 shows the $-\log _{10}(P)$ of DGAT1, SCD1, $C S N 3$, and $L G B$ polymorphisms on the 1,060 infrared wavenumbers. The DGAT1 had extremely significant effects on many wavenumbers. For 121 wavenumbers $D G A T 1$ had a $-\log _{10}(P)$ larger than 100 and the highest $-\log _{10}(P)$ was 110.4 . The DGAT1 had no significant effect on 216 wavenumbers, most of which belong to the water absorption region. However, wavenumbers from 3,466 to $3,543 \mathrm{~cm}^{-1}$ were significantly affected by the $D G A T 1$ polymorphism with the highest $-\log _{10}(P)$ value of 17.0. The $S C D 1$ polymorphism did not significantly affect any of the wavenumbers.

Significant effects of the CSN3 polymorphism were found on 5 regions: wavenumbers are from 1,238 to $1,292 \mathrm{~cm}^{-1}, 1,431$ to $1,477 \mathrm{~cm}^{-1}, 1,504$ to $1,573 \mathrm{~cm}^{-1}$, 2,371 to $2,607 \mathrm{~cm}^{-1}$, and 3,682 to $5,008 \mathrm{~cm}^{-1}$. The largest $-\log _{10}(P)$ of 19.2 was found for wavenumber 3,717 $\mathrm{cm}^{-1}$. The $L G B$ polymorphism showed significant effects on wavenumbers between 1,377 and $1,415 \mathrm{~cm}^{-1}$.

\section{DISCUSSION}

In this study, we investigated the effects of genetic and environmental factors on milk infrared wavenum- bers. Besides quantifying the total genetic variance of individual wavenumbers, we also estimated the effects of DGAT1, SCD1, CSN3, and $L G B$ polymorphisms. The polymorphisms in DGAT1, CSN3, and $L G B$ significantly affected several wavenumbers, whereas the $S C D 1$ polymorphism had no significant effect on any of the wavenumbers. Differences between herds accounted for more than $10 \%$ of the variation in many infrared wavenumbers. These herd effects might reflect feeding or management differences between farms.

Wavenumbers of the water absorption region showed large variation (Figure 1), and a small fraction of the phenotypic variance was explained by genetics (Figure 3 ). These wavenumbers represent the absorption peaks of water and because water is the main component of milk and a very strong infrared absorber, water will mask the effects of other components (e.g., Safar et al., 1994; Karoui et al., 2010). Wavenumbers 3,466 to 3,543 $\mathrm{cm}^{-1}$ of the water absorption region were significantly affected by lactation stage (Figure 2) and the DGAT1 polymorphism (Figure 4). The wavenumbers of the water absorption region are usually excluded when setting up prediction equations (e.g., De Marchi et al., 2009). Our results suggest that some of these wavenumbers contain information on milk composition.

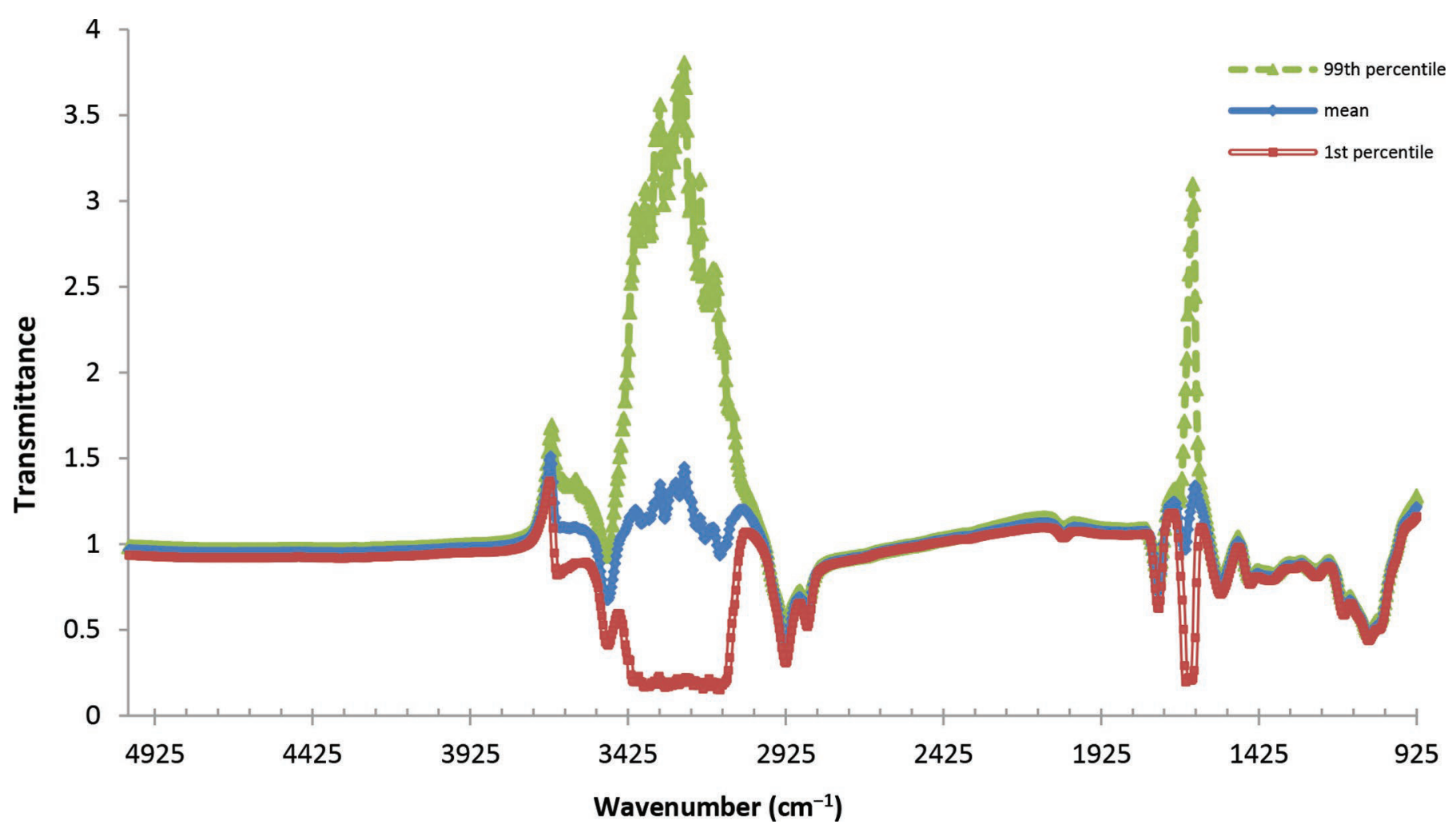

Figure 1. The mean transmittance for 1,060 infrared wavenumbers, and the corresponding 1st percentile and the 99th percentile, based on records of 1,748 dairy cows. Color version available online. 

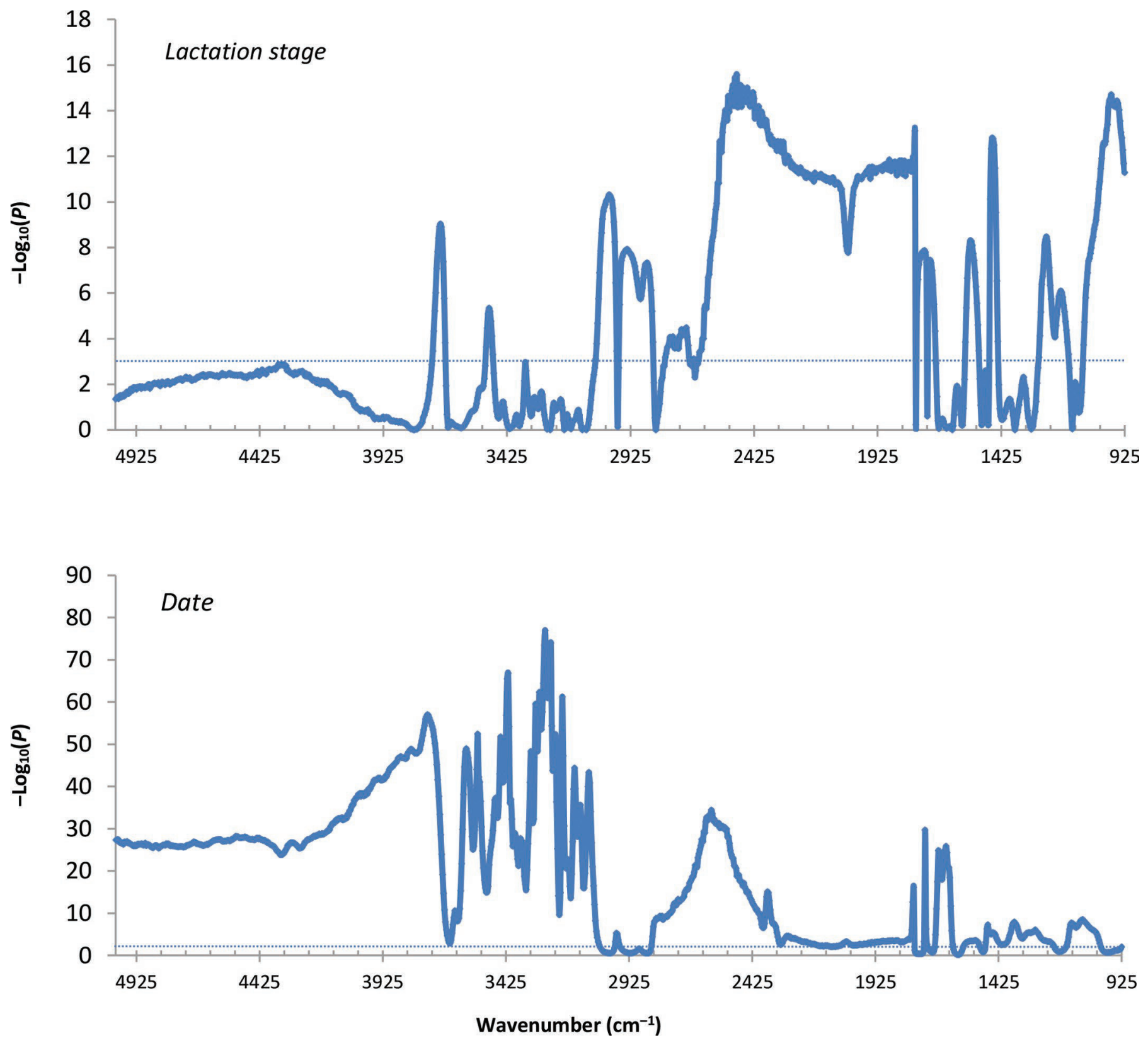

Figure 2. The significance of the effect of lactation stage and date of analysis on milk infrared wavenumbers. The horizontal line indicates a threshold at $-\log _{10}(P)$ of 3 . Color version available online.

\section{Fixed Effects}

Lactation stage showed significant effects on many wavenumbers (Figure 2). It is well known that fat and protein content change during lactation (e.g., Schutz et al., 1990). Furthermore, Stoop et al. (2009) showed that milk fat composition is affected by lactation stage. Lactation stage has a smaller effect on milk protein composition (e.g., Walker et al., 2004). These changes in milk composition during lactation are reflected by the milk infrared wavenumbers. In our data set, lactation stage ranged from 63 to $282 \mathrm{~d}$ and no early lactation records were available. Because the milk composition changes considerably from early to middle lactation, it is expected that stronger effects of lactation stage will be observed when records covering the complete lactation are included in the analysis.

To our knowledge, no other studies specifically quantified the effect of date of analysis on infrared spectra. In our study, the milk samples were analyzed in 
a short time period of less than 2 mo. Furthermore, the MilkoScan FT 6000 was calibrated at regular times according to the manufacturer's instructions. However, for many wavenumbers, we found significant effects of date of analysis, which suggests instability of the FTIR spectrometer across dates. Many wavenumbers showed a time trend, which would point at a drift of the spectrometer. The wavenumbers in water absorption region showed highly significant effects of date of analysis. Grelet et al. (2015) standardized milk infrared spectra from different laboratories and reported that standardization coefficients were less adapted in the second study 1 mo later. This also might be due to a time trend or perturbations of the spectrometers.

In the current study, milk samples from one herd were analyzed on the same day shortly after collection. Therefore, the effects of herd and date of analysis were confounded. We found that the variance due to differences between herds increased considerably for some wavenumbers when date of analysis was not accounted for in the model.

\section{Heritability}

In our study, most wavenumbers had moderate to high heritabilities ranging from 0.20 to 0.60 . The estimated heritabilities for wavenumbers in this study were considerably higher than those reported in other studies. Bittante and Cecchinato (2013) analyzed transmittance values at 1,056 FTIR wavenumbers (930 to 5,000 $\mathrm{cm}^{-1}$ ) of milk from 1,064 Italian Brown Swiss cows. Both studies showed a similar pattern of heritabilities for the different wavenumbers. Bittante and Cecchinato (2013) reported that heritabilities of milk infrared wavenumbers ranged from 0 to 0.27 . In their study, 578 wavenumbers had heritabilities between 0.05 and 0.10 and 261 wavenumbers had heritabilities between 0.10 and 0.20. The lower heritability reported by Bittante and Cecchinato (2013) as compared with the current study might among other reasons be due to different instruments used (Foss FT 6000 vs. FT 120 spectrometer). However, the most likely reason is the difference in breeds studied, which is in agreement with previous

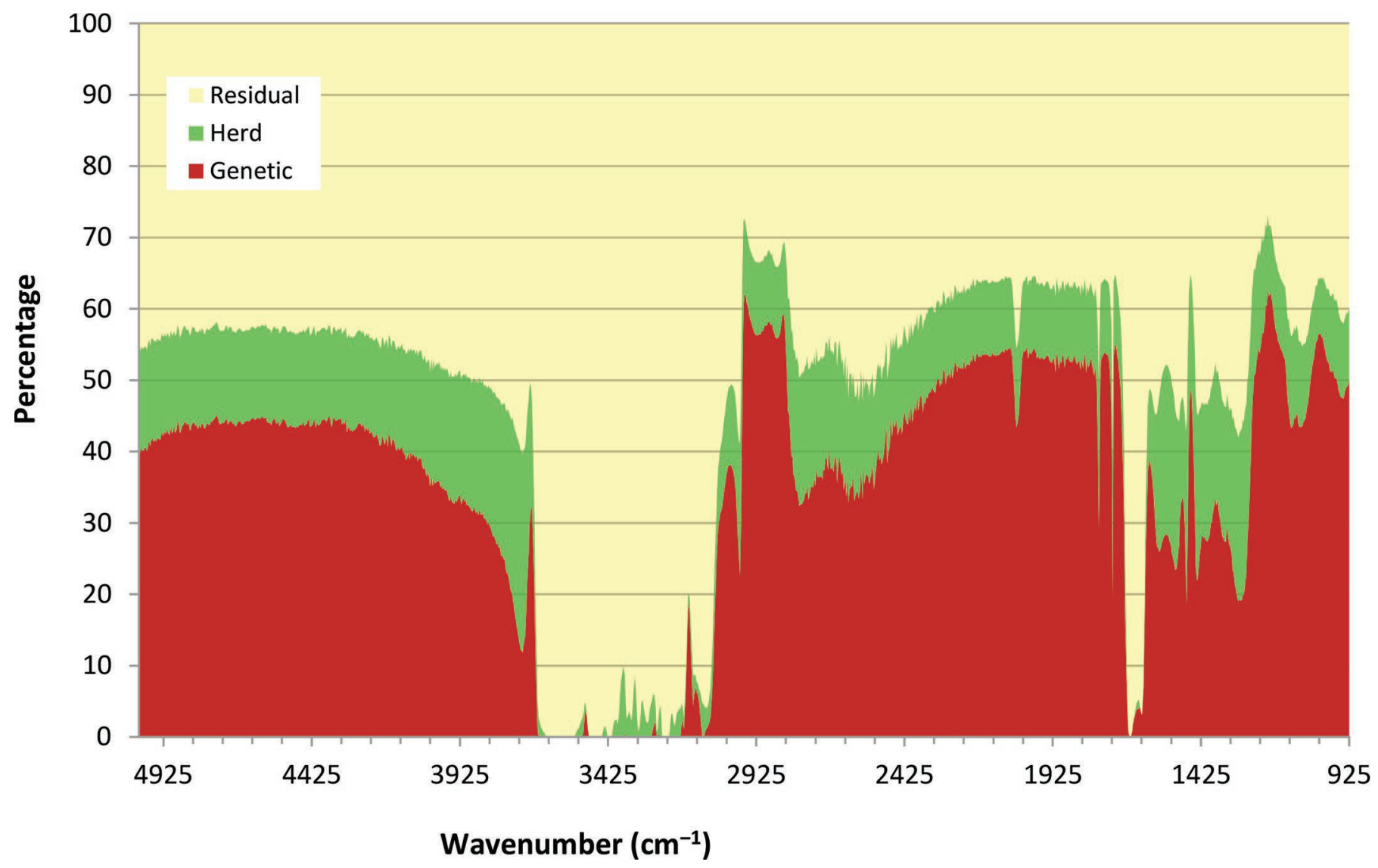

Figure 3. Percentage of the total variation of infrared wavenumbers explained by genetic, herd, and residual effects. Color version available online. 

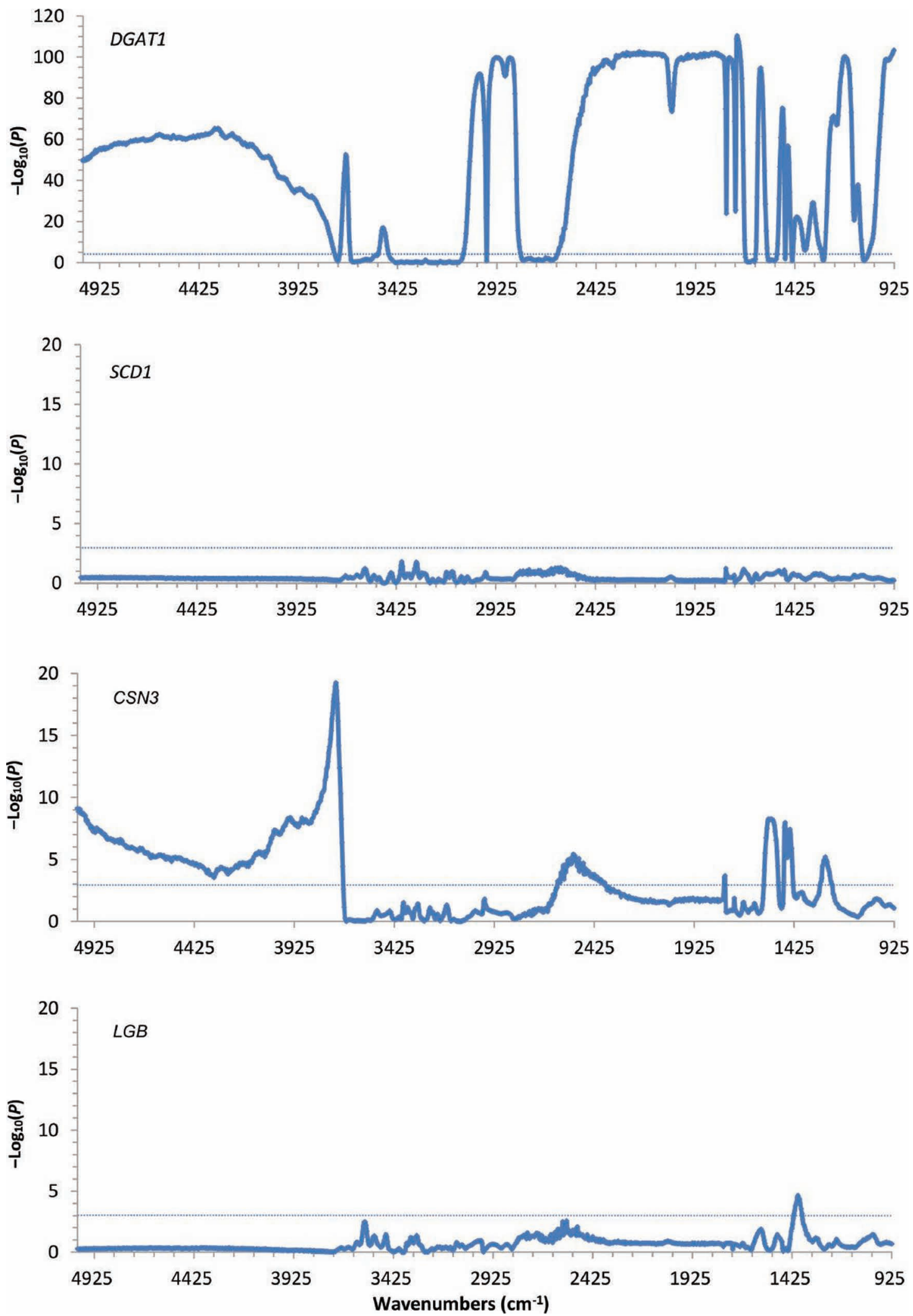

Figure 4. The significance of the effect of diacylglycerol O-acyltransferase 1 (DGAT1), stearoyl-CoA desaturase (SCD1), К-casein (CSN3), and $\beta$-lactoglobulin $(L G B)$ polymorphisms on infrared wavenumbers. The horizontal lines indicate a threshold at $-\log _{10}(P)$ of 3. Color version available online. 
studies that reported higher heritabilities for milk fat and protein content in Dutch Holstein Friesian than Italian Brown Swiss. Based on largely the same cows as included in the current study, Stoop et al. (2007) estimated heritabilities of 0.52 for fat $\%, 0.60$ for protein\%, and 0.64 for lactose\%. For Italian Brown Swiss, Samorè et al. (2012) reported heritabilities of 0.12 for fat \%, 0.28 for protein $\%$, and 0.25 for lactose\%. These differences are in line with the observed differences in heritability estimates of infrared wavenumbers between Bittante and Cecchinato (2013) and our study.

Soyeurt et al. (2010) estimated heritabilities for transmittance values of milk infrared wavenumbers from 1,594 first parity Holstein cows in the Walloon region of Belgium. Heritabilities in the study by Soyeurt et al. (2010) ranged from 0.00 to 0.42 . These estimates are on average approximately 0.1 lower than estimates from our study. Bastin et al. (2011) analyzed milk samples from the Walloon region and estimated heritabilities of approximately 0.40 for fat $\%$ and 0.45 for protein $\%$. These estimates are 0.12 lower for fat $\%$ and 0.15 lower for protein\% than the estimates reported by Stoop et al. (2007). These differences are in line with the difference in heritability estimates for wavenumbers in the current study and those reported by Soyeurt et al. (2010).

\section{Effects of Individual Genes}

Several studies showed that the DGAT1 K232A polymorphism is especially associated with milk fat content and fat composition (e.g., Grisart et al., 2002; Schennink et al., 2008). The $K$ allele is associated with a higher fraction of C16:0, a higher SFA/UFA ratio, and lower fractions of C14:0, unsaturated C18, and CLA (e.g., Schennink et al., 2008). In our study, DGAT1 showed highly significant effects on numerous infrared wavenumbers, which is in line with its large effect on milk composition. The largest DGAT1 effect was found for wavenumber $1,716 \mathrm{~cm}^{-1}$ with $-\log _{10}(P)$ of 110.4 . Furthermore, highly significant DGAT1 effects on wavenumbers between 1,735 and $1,762 \mathrm{~cm}^{-1}$ were observed. These wavenumbers are associated with carboxylic acid and ester $\mathrm{C}=\mathrm{O}$ bond stretching (Safar et al., 1994). The DGAT1 also had highly significant effects on wavenumbers between 1,160 and $1,180 \mathrm{~cm}^{-1}$. This region represents the triglyceride ester linkage $\mathrm{C}-\mathrm{O}$ stretching (Safar et al., 1994). The significant DGAT1 effects on most of the wavenumbers from 2,800 to $2,975 \mathrm{~cm}^{-1}$ can be explained as these wavenumbers are associated with alkyl C-H stretching (e.g., Safar et al., 1994; Yang and Irudayaraj, 2000), which is abundant in fat. Figure 4 also showed highly significant effects of DGAT1 on wavenumbers around $3,686 \mathrm{~cm}^{-1}$. However, it is not clear which chemical bonds are associated with these wavenumbers.

It is known that $S C D 1$ is responsible for the desaturation of fatty acids. Schennink et al. (2008) reported that the SCD1 polymorphism has no significant effect on fat $\%$ but a large effect on fat composition. Using mainly the same animals as in the current study, Duchemin et al. (2013) showed that $S C D 1$ has highly significant effects on C10:1, C12:1, C14:1, and C16:1 fatty acids. In the current study, we did not find significant effect of the $S C D 1$ polymorphism on any of the wavenumbers (Figure 4). This suggests that there is little direct information in the FTIR spectra on C10:1, C12:1, C14:1, and C16:1 fatty acids. Infrared prediction equations for these fatty acids therefore might be based on their correlations with total milk fat content. This would be in agreement with Eskildsen et al. (2014), who suggested that predictions of individual fatty acids by FTIR measurements in milk are indirect and are based on covariation between the fatty acids and total fat content. Interestingly, $S C D 1$ has no significant effect on the total fraction of UFA, which can be explained by the negative association of the $S C D 1 \mathrm{~V}$ allele with medium-chain UFA (e.g., C10:1, C12:1, and C14:1) and the positive association with longer chain UFA (e.g., C16:1; Duchemin et al., 2013). Therefore, these results do not provide evidence that the FTIR spectra contain little direct information on the total fraction of UFA.

The $\kappa$-casein polymorphism has been shown to be associated with protein percentage (e.g., Bovenhuis et al., 1992) and the relative concentrations of the 6 main milk proteins (e.g., Heck et al., 2009). The B allele of CSN3 is associated with a higher protein percentage and a higher relative concentration of CSN3 and CSN1S2, as well as a lower relative concentration of LALBA and CSN1S1 (Heck et al., 2009). Casein is expected to have absorption peaks around wavenumbers $1,250,1,550$, and $1,650 \mathrm{~cm}^{-1}$ due to amide III, amide II, and amide I bands, respectively (Osborne and Fearn, 1986), whereas in this study we found significant CSN3 effects on wavenumbers around 1,269 and $1,550 \mathrm{~cm}^{-1}$ (Figure 4). The effects on wavenumbers around 1,269 $\mathrm{cm}^{-1}$ might be due to amide III or phosphate bands (Hewavitharana and van Brakel, 1997). Furthermore, the significant effects of $C S N 3$ on wavenumbers between 1,504 and $1,573 \mathrm{~cm}^{-1}$ coincide with the amide II band. This is mainly due to N-H bending and C-N stretching (Garidel and Schott, 2006). We did not detect significant CSN3 effects on wavenumbers around $1,650 \mathrm{~cm}^{-1}$ due to amide I bands, which might be because this is in the water absorption region.

We also found significant CSN3 effects on some other wavenumbers (Figure 4). A spectral peak close to 1,469 
$\mathrm{cm}^{-1}$ was also observed by De Marchi et al. (2010) and this region might be associated with proteins. The significant effect of $C S N 3$ around wavenumber $2,529 \mathrm{~cm}^{-1}$ might be explained by its relation with $\mathrm{S}-\mathrm{H}$ stretching (Hewavitharana and van Brakel, 1997), which commonly binds to whey protein. Therefore, this effect might be explained by the CSN3 effect on the relative concentration of whey protein. We found a highly significant effect of CSN3 for wavenumber $3,717 \mathrm{~cm}^{-1}$, but this wavenumber is not known to be associated with any specific chemical bond.

Several studies showed significant associations between the $\beta$-lactoglobulin polymorphism and milk protein composition (e.g., Lundén et al., 1997; Heck et al., 2009). Cows with the $L G B B B$ genotype have a higher casein and lower $\beta$-lactoglobulin content than cows with the $L G B A A$ genotype and therefore the $\beta$-lactoglobulin $B$ allele is preferred for cheese production (e.g., Van den Berg et al., 1992; Boland and Hill. 2001; Wedholm et al., 2006). In this study, $L G B$ polymorphism had significant effects on wavenumbers between 1,377 and $1,415 \mathrm{~cm}^{-1}$. The highest $-\log _{10}(P)$ in this region was approximately 4.6. This significant effect of $L G B$ might be due to the association with C-N stretching at $1,414 \mathrm{~cm}^{-1}$ (Dufour, 2009). Notably, we did not find any wavenumbers that were significantly affected by both the CSN3 and LGB polymorphisms.

The wavenumbers from 3,700 to $5,008 \mathrm{~cm}^{-1}$ are difficult to interpret because the spectra are complex and combined by overlapping peaks and variations. Wavenumbers 4,033 to $4,350 \mathrm{~cm}^{-1}$ can be attributed to combination bands of $\mathrm{C}-\mathrm{H}$, which is abundant in fatty acids. Wavenumbers 4,500 to $5,000 \mathrm{~cm}^{-1}$ can be attributed to vibrations of $\mathrm{N}-\mathrm{H}$ and $\mathrm{C}=\mathrm{O}$ group of proteins (Subramanian and Rodriguez-Saona, 2009). These might explain the significant effects of DGAT1 and $C S N 3$ on these wavenumbers.

It has been shown that it is possible to predict genotypes of polymorphism known to be associated with milk composition based on milk FTIR. Rutten et al. (2011b) showed that $L G B$ genotypes can be predicted based on FTIR. Our study showed that DGAT1 and $C S N 3$ genotypes have larger effects than $L G B$ on FTIR wavenumbers. This suggests that FTIR might be used to predict DGAT1 and CSN3 genotypes. The $K$ allele of $D G A T 1 \mathrm{~K} 232 \mathrm{~A}$ polymorphism is associated with higher fat $\%$, protein $\%$, and fat yield, but lower milk yield and protein yield (Bovenhuis et al., 2015). The CSN3 B allele is associated with a higher protein percentage (Heck et al., 2009). As these genotypes have distinct effects on milk composition, knowledge of these genotypes might be of interest. The accuracy of predicted genotypes might be increased by combining FTIR information with pedigree information. Conversely, genotypes of individual cows and their genotypic effects on milk composition might be combined with FTIR to improve prediction of milk composition.

\section{Herd}

Our milk samples were collected from numerous farms throughout the Netherlands, which is a good representation of herds in the Netherlands. The herd variance quantifies the relative importance of herd effect, which reflects differences due to feeding, hygiene, and husbandry. Many studies have shown the effect of feed on milk composition (e.g., Grummer, 1991; Palmquist et al., 1993; Slots et al., 2009). Valenti et al. (2013) demonstrated that based on infrared data it is possible to distinguish milk from hay- and pasture-based systems and those from maize silage- and pasture-based systems.

Herd variation for wavenumbers might also reflect differences between herds in the cows' health status and body condition. Some metabolic diseases such as ketosis may affect milk composition. Several studies showed that FTIR can be used to screen cows for subclinical ketosis (e.g., Hansen, 1999; Heuer et al., 2001; de Roos et al., 2007). Furthermore, in addition to cell count measurements, FTIR might provide information regarding mastitis (Batavani et al., 2007). McParland et al. (2011) indicated that energy status of dairy cows can be predicted based on FTIR spectra. On the basis of routine prediction based on FTIR, the predicted energy status could provide information about dairy farm management or body condition of individual cows.

\section{CONCLUSIONS}

This study showed that genetic differences between cows explain a large part of the variation in milk infrared wavenumbers. Furthermore we showed that the $D G A T 1$ polymorphism significantly affected many wavenumbers. The polymorphisms of $C S N 3$ and $L G B$ also significantly affected some of the wavenumbers, but no significant effect of $S C D 1$ on any of the wavenumbers was found. Differences between herds accounted for a considerable part of phenotypic variance of individual wavenumbers and these wavenumbers might be of interest to discriminate milk from farms with different feeding or management regimens. Some wavenumbers are strongly influenced by water absorption and are usually excluded when setting up prediction equations. However, we found that some of the wavenumbers in the water absorption region are significantly affected by DGAT1 polymorphism and lactation stage. This suggested that these wavenumbers contain information on milk composition. 


\section{ACKNOWLEDGMENTS}

The China Scholarship Council is acknowledged for funding the PhD project of Qiuyu Wang. The Cooperative Cattle Improvement Organization (CRV) is acknowledged for the sampling cows provided and imputation of genotypes. Milk Control Station (Zutphen, the Netherlands) is acknowledged for infrared spectra data. This study is part of the Dutch Milk Genomics Initiative and the project "Melk op Maat," funded by Wageningen University (Wageningen, the Netherlands), the Dutch Dairy Association (NZO, Zoetermeer, the Netherlands), CRV, the Dutch Technology Foundation (STW, Utrecht, the Netherlands), the Dutch Ministry of Economic Affairs (The Hague, the Netherlands), and the Provinces of Gelderland and Overijssel (Arnhem, the Netherlands).

\section{REFERENCES}

Bastin, C., N. Gengler, and H. Soyeurt. 2011. Phenotypic and genetic variability of production traits and milk fatty acid contents across days in milk for Walloon Holstein first-parity cows. J. Dairy Sci. 94:4152-4163.

Batavani, R. A., S. Asri, and H. Naebzadeh. 2007. The effect of subclinical mastitis on milk composition in dairy cows. Iran. J. Vet. Res. 8:205-211.

Berget, I., H. Martens, A. Kohler, S. K. Sjurseth, N. K. Afseth, B. Narum, and S. Lien. 2010. Caprine CSN1S1 haplotype effect on gene expression and milk composition measured by Fourier transform infrared spectroscopy. J. Dairy Sci. 93:4340-4350.

Bittante, G., and A. Cecchinato. 2013. Genetic analysis of the Fouriertransform infrared spectra of bovine milk with emphasis on individual wavenumbers related to specific chemical bonds. J. Dairy Sci. 96:5991-6006.

Boland, M., and J. Hill. 2001. Genetic selection to increase cheese yield: The Kaikoura experience. Aust. J. Dairy Technol. 56:171176

Bonfatti, V., G. Di Martino, and P. Carnier. 2011. Effectiveness of mid-infrared spectroscopy for the prediction of detailed protein composition and contents of protein genetic variants of individual milk of Simmental cows. J. Dairy Sci. 94:5776-5785.

Bovenhuis, H., J. A. M. van Arendonk, and S. Korver. 1992. Associations between milk protein polymorphisms and milk production traits. J. Dairy Sci. 75:2549-2559.

Bovenhuis, H., M. H. P. W. Visker, H. J. F. van Valenberg, A. J. Buitenhuis, and J. A. M. van Arendonk. 2015. Effects of the DGAT1 polymorphism on test-day milk production traits throughout lactation. J. Dairy Sci. 98:6572-6582.

Chilliard, Y., F. Glasser, A. Ferlay, L. Bernard, J. Rouel, and M. Doreau. 2007. Diet, rumen biohydrogenation and nutritional quality of cow and goat milk fat. Eur. J. Lipid Sci. Technol. 109:828855

Chilliard, Y., C. Martin, J. Rouel, and M. Doreau. 2009. Milk fatty acids in dairy cows fed whole crude linseed, extruded linseed, or linseed oil, and their relationship with methane output. J. Dairy Sci. 92:5199-5211.

De Marchi, M., V. Bonfatti, A. Cecchinato, G. Di Martino, and P. Carnier. 2010. Prediction of protein composition of individual cow milk using mid-infrared spectroscopy. Ital. J. Anim. Sci. 8:399-401.

De Marchi, M., C. C. Fagan, C. P. O'Donnell, A. Cecchinato, R. Dal Zotto, M. Cassandro, M. Penasa, and G. Bittante. 2009. Prediction of coagulation properties, titratable acidity, and $\mathrm{pH}$ of bovine milk using mid-infrared spectroscopy. J. Dairy Sci. 92:423-432.
De Marchi, M., V. Toffanin, M. Cassandro, and M. Penasa. 2014 Invited review: Mid-infrared spectroscopy as phenotyping tool for milk traits. J. Dairy Sci. 97:1171-1186.

de Roos, A. P. W., H. J. C. M. van Den Bijgaart, J. Hørlyk, and G. De Jong. 2007. Screening for subclinical ketosis in dairy cattle by Fourier transform infrared spectrometry. J. Dairy Sci. 90:1761-1766.

Duchemin, S., H. Bovenhuis, W. M. Stoop, A. C. Bouwman, J. A. M. van Arendonk, and M. H. P. W. Visker. 2013. Genetic correlation between composition of bovine milk fat in winter and summer, and DGAT1 and SCD1 by season interactions. J. Dairy Sci. 96:592-604.

Dufour, E. 2009. Principles of infrared spectroscopy. Pages 1-27 in Infrared Spectroscopy for Food Quality Analysis and Control. D. W. Sun, ed. Acad. Press, San Diego, CA.

Emery, R. S. 1978. Feeding for increased milk protein. J. Dairy Sci. $61: 825-828$.

Eskildsen, C. E., M. A. Rasmussen, S. B. Engelsen, L. B. Larsen, N. A. Poulsen, and T. Skov. 2014. Quantification of individual fatty acids in bovine milk by infrared spectroscopy and chemometrics: Understanding predictions of highly collinear reference variables. J. Dairy Sci. 97:7940-7951.

Garidel, P., and H. Schott. 2006. Fourier-transform midinfrared spectroscopy for analysis and screening of liquid protein formulations part 2: Detailed analysis and applications. Bioprocess Int. 4:48-55.

German, J. B., and C. J. Dillard. 2006. Composition, structure and absorption of milk lipids: A source of energy, fat-soluble nutrients and bioactive molecules. Crit. Rev. Food Sci. Nutr. 46:57-92.

Gilmour, A. R., B. J. Gogel, B. R. Cullis, and R. Thompson. 2009. ASReml user guide release 3.0. VSN International Ltd., Hemel Hempstead, UK.

Grelet, C., J. F. Pierna, P. Dardenne, V. Baeten, and F. Dehareng. 2015. Standardization of milk mid-infrared spectra from a European dairy network. J. Dairy Sci. 98:2150-2160.

Grisart, B., W. Coppieters, F. Farnir, L. Karim, C. Ford, P. Berzi, N Cambisano, M. Mni, S. Reid, P. Simon, R. Spelman, M. Georges, and R. Snell. 2002. Positional candidate cloning of a QTL in dairy cattle: Identification of a missense mutation in the bovine DGAT1 gene with major effect on milk yield and composition. Genome Res. 12:222-231.

Grummer, R. R. 1991. Effect of feed on the composition of milk fat. J. Dairy Sci. 74:3244-3257.

Hansen, P. W. 1999. Screening of dairy cows for ketosis by use of infrared spectroscopy and multivariate calibration. J. Dairy Sci. 82:2005-2010

Heck, J. M. L., A. Schennink, H. J. F. van Valenberg, H. Bovenhuis, M. H. P. W. Visker, J. A. M. van Arendonk, and A. C. M. van Hooijdonk. 2009. Effects of milk protein variants on the protein composition of bovine milk. J. Dairy Sci. 92:1192-1202.

Heuer, C., H. J. Luinge, E. T. G. Lutz, Y. H. Schukken, J. H. van der Maas, H. Wilmink, and J. P. T. M. Noordhuizen. 2001. Determination of acetone in cow milk by Fourier transform infrared spectroscopy for the detection of subclinical ketosis. J. Dairy Sci. $84: 575-582$.

Hewavitharana, A. K., and B. van Brakel. 1997. Fourier transform infrared spectrometric method for the rapid determination of casein in raw milk. Analyst (Lond.) 122:701-704.

ICAR (International Committee for Animal Recording). 2012. International agreement of recording practices - Guidelines approved by the General Assembly held in Cork, Ireland on June 2012. ICAR, Rome. Italy.

Jelen, P. 2007. Innovative uses of milk in human nutrition and health Proceedings of the 35th Biennial Session of ICAR, Kuopio, Finland. EAAP publication 121. EAAP, Rome, Italy.

Karoui, R., G. Downey, and C. Blecker. 2010. Mid-infrared spectroscopy coupled with chemometrics: A tool for the analysis of intact food systems and the exploration of their molecular structureQuality relationships-A review. Chem. Rev. 110:6144-6168.

Lundén, A., M. Nilsson, and L. Janson. 1997. Marked effect of $\beta$-lactoglobulin polymorphism on the ratio of casein to total protein in milk. J. Dairy Sci. 80:2996-3005. 
McParland, S., G. Banos, E. Wall, M. P. Coffey, H. Soyeurt, R. F Veerkamp, and D. P. Berry. 2011. The use of mid-infrared spectrometry to predict body energy status of Holstein cows. J. Dairy Sci. 94:3651-3661.

Miglior, F., B. L. Muir, and B. J. van Doormaal. 2005. Selection indices in Holstein cattle of various countries. J. Dairy Sci. 88:1255-1263.

Osborne, B. G., and T. Fearn. 1986. Near Infrared Spectroscopy in Food Analysis. Longman, Harlow, UK

Palmquist, D. L., A. D. Beaulieu, and D. M. Barbano. 1993. Feed and animal factors influencing milk fat composition. J. Dairy Sci. 76:1753-1771.

Rutten, M. J. M., H. Bovenhuis, J. M. L. Heck, and J. A. M. van Arendonk. 2011a. Predicting bovine milk protein composition based on Fourier transform infrared spectra. J. Dairy Sci. 94:5683-5690.

Rutten, M. J. M., H. Bovenhuis, J. M. L. Heck, and J. A. M. van Arendonk. 2011b. Prediction of $\beta$-lactoglobulin genotypes based on milk Fourier transform infrared spectra. J. Dairy Sci. 94:41834188.

Rutten, M. J. M., H. Bovenhuis, K. A. Hettinga, H. J. F. van Valenberg, and J. A. M. van Arendonk. 2009. Predicting bovine milk fat composition using infrared spectroscopy based on milk samples collected in winter and summer. J. Dairy Sci. 92:6202-6209.

Safar, M., D. Bertrand, P. Robert, M. F. Devaux, and C. Genot. 1994. Characterization of edible oils, butters and margarines by Fourier transform infrared spectroscopy with attenuated total reflectance. J. Am. Oil Chem. Soc. 71:371-377.

Samorè, A. B., F. Canavesi, A. Rossoni, and A. Bagnato. 2012. Genetics of casein content in Brown Swiss and Italian Holstein dairy cattle breeds. Ital. J. Anim. Sci. 11:196-202.

Schennink, A., J. M. L. Heck, H. Bovenhuis, M. H. P. W. Visker, H. J. F. van Valenberg, and J. A. M. van Arendonk. 2008. Milk fatty acid unsaturation: Genetic parameters and effects of stearoyl-CoA desaturase $(S C D 1)$ and acyl CoA: diacylglycerol acyltransferase 1 (DGAT1). J. Dairy Sci. 91:2135-2143.

Schutz, M. M., L. B. Hansen, G. R. Steuernagel, and A. L. Kuck. 1990. Variation of milk, fat, protein, and somatic cells for dairy cattle. J. Dairy Sci. 73:484-493.

Slots, T. G. Butler, C. Leifert, T. Kristensen, L. H. Skibsted, and J. H. Nielsen. 2009. Potentials to differentiate milk composition by different feeding strategies. J. Dairy Sci. 92:2057-2066.

Soyeurt, H., P. Dardenne, F. Dehareng, G. Lognay, D. Veselko, M. Marlier, C. Bertozzi, P. Mayeres, and N. Gengler. 2006. Estimating fatty acid content in cow milk using mid-infrared spectrometry. J. Dairy Sci. 89:3690-3695.
Soyeurt, H., I. Misztal, and N. Gengler. 2010. Genetic variability of milk components based on mid-infrared spectral data. J. Dairy Sci. 93:1722-1728.

Stoop, W. M., H. Bovenhuis, J. M. L. Heck, and J. A. M. van Arendonk. 2009. Effect of lactation stage and energy status on milk fat composition of Holstein-Friesian cows. J. Dairy Sci. 92:1469-1478.

Stoop, W. M., H. Bovenhuis, and J. A. M. van Arendonk. 2007. Genetic parameters for milk urea nitrogen in relation to milk production traits. J. Dairy Sci. 90:1981-1986.

Subramanian, A., and L. Rodriguez-Saona. 2009. Fourier transform infrared (FTIR) spectroscopy. Pages 145-178 in Infrared Spectroscopy for Food Quality Analysis and Control. D. W. Sun, ed. Acad. Press, San Diego, CA.

Valenti, B., B. Martin, D. Andueza, C. Leroux, C. Labonne, F. Lahalle, H. Larroque, P. Brunschwig, C. Lecomte, M. Brochard, and A. Ferlay. 2013. Infrared spectroscopic methods for the discrimination of cows' milk according to the feeding system, cow breed and altitude of the dairy farm. Int. Dairy J. 32:26-32.

Van den Berg, G., J. T. M. Escher, P. J. De Koning, and H. Bovenhuis. 1992. Genetic polymorphism of $\kappa$-casein and $\beta$-lactoglobulin in relation to milk composition and processing properties. Nederlands melk en Zuiveltijdschrift. 46:145-168.

Van Haelst, Y. N. T., A. Beeckman, A. T. M. van Knegsel, and V. Fievez. 2008. Short communication: Elevated concentrations of oleic acid and long-chain fatty acids in milk fat of multiparous subclinical ketotic cows. J. Dairy Sci. 91:4683-4686.

Visker, M. H. P. W., B. W. Dibbits, S. M. Kinders, H. J. F. van Valenberg, J. A. M. van Arendonk, and H. Bovenhuis. 2011. Association of bovine $\beta$-casein protein variant I with milk production and milk protein composition. Anim. Genet. 42:212-218.

Vlaeminck, B., V. Fievez, S. Tamminga, R. J. Dewhurst, A. van Vuuren, D. de Brabander, and D. Demeyer. 2006. Milk odd-and branched-chain fatty acids in relation to the rumen fermentation pattern. J. Dairy Sci. 89:3954-3964.

Walker, G. P., F. R. Dunshea, and P. T. Doyle. 2004. Effects of nutrition and management on the production and composition of milk fat and protein: A review. Crop Pasture Sci. 55:1009-1028.

Wedholm, A., L. B. Larsen, H. Lindmark-Månsson, A. H. Karlsson, and A. Andrén. 2006. Effect of protein composition on the cheesemaking properties of milk from individual dairy cows. J. Dairy Sci. 89:3296-3305

Yang, H., and J. Irudayaraj. 2000. Characterization of semisolid fats and edible oils by Fourier transform infrared photoacoustic spectroscopy. J. Am. Oil Chem. Soc. 77:291-295. 